\title{
Principles of Strengths-Based Nursing Leadership for Strengths-Based Nursing Care: A New Paradigm for Nursing and Healthcare for the 21st Century
}

Laurie N. Gottlieb, RN, PhD

Professor, Flora Madeline Shaw Chair of Nursing, School of Nursing, McGill University Nurse-Scholar-in-Residence, Jewish General Hospital

Montreal, QC

Bruce Gottlieb, PhD

Project Director, Lady Davis Institute for Medical Research, Jewish General Hospital Adjunct Professor, School of Nursing, McGill University

Montreal, QC

Judith Shamian, RN, PhD

President and CEO, VON Canada

President, Canadian Nurses Association (2010-2012)

Ottawa, ON

\section{Abstract}

The current healthcare system is slowly evolving into a new system built on a vision of health promotion, primary care and community-based home care, with hospitals still being a core pillar of the healthcare system but not its primary service. This transformation requires a new approach to practice, namely, Strengths-Based Nursing Care (SBC). SBC is about mobilizing, capitalizing and developing a person's strengths to promote health and facilitate healing. For nurses to practise SBNC requires strong nursing leadership that creates conditions to enable them to do so. StrengthsBased Nursing Leadership complements and acts in synergy with, SBNC. This paper describes eight principles of Strengths-Based Nursing Leadership to support SBNC. 
After two decades of mergers, restructuring and reorganizing, the current healthcare system is gradually giving way to a new healthcare system. The new system is being built on a vision of health promotion, primary care and community-based home care, with hospitals still being a core pillar of the healthcare system but not its primary service (Hancock 1999; IOM 2012). The vision also includes a system in which people and communities assume greater control and responsibility for their own health and healthcare decisions (Frist 2005).

During this 20-year period, the health of Canadians deteriorated despite significant government reinvestments following a period of severe budgetary cuts to the healthcare system (OECD 2011). Moreover, the old healthcare system, essentially a disease/illness model, became more fragmented, more depersonalized and less accessible. Both events can be attributed, in part, to nurse burnout and the undermining of nursing and its leadership (Vahey et al. 2004). Further, the introduction of program management to address the inefficiencies of the healthcare system was accompanied by a serious decline of nursing leadership from among the senior ranks of healthcare teams.

If there is to be a transformation that puts people and communities at the centre of healthcare, we need to move to a new approach to practice and to nursing leadership. There is a growing body of literature that such an approach needs to address the importance of inter-professional practice (Gilbert et al. 2010; McKay and Crippen 2008). Within this context, we also need to consider a new approach to nursing leadership that will support a more comprehensive nursing role that will fulfill nursing's mandate to the health of society. One such approach to nursing practice is called Strengths-Based Nursing Care (SBC) (Gottlieb 2012). This approach also complements an inter-professional practice approach. Both focus on the holistic, complex health needs of people and empower them to take charge of their health and healthcare decisions.

SBC is about recognizing, mobilizing, capitalizing and developing a person's strengths to promote health and facilitate healing. For nurses to practise SBC requires strong nursing leadership that creates conditions to enable them to do so. We call this new model of leadership Strengths-Based Nursing Leadership and Management, which embraces, complements and acts in synergy with SBC.

In this paper we propose that strengths-based leadership can lead to strong interprofessionalism and higher-quality, effective and efficient, cost-effective care, with better health outcomes. We describe some of the features of SBC and the eight principles of Strengths-Based Nursing Leadership to support SBC. 


\section{The Strengths-Based Movement}

The strengths-based movement has the potential to become a "game changer" in nursing and to transform healthcare. It redirects the focus from deficits, problems and weaknesses to use strengths that include assets and resources to manage problems and overcome and contain weaknesses. The common wisdom is that most problems can be "fixed" by throwing more money at them or cutting waste from the system. After many years of trying to fix problems, results have been limited and, in many cases, disheartening. The deficit approach has tended to yield short-term, expensive solutions that have proven to be non-sustainable over the long-term.

Why is this so? The deficit, problem-based approach talks to a person's innate fears and threats. People have difficulty embarking on change when overwhelmed by fear and paralyzed by threats. Individuals, families, communities and institutions are more likely to take charge when they focus on the positives and are provided with the opportunities and support that enable them to feel empowered to create their own solutions.

The strengths-based leadership approach originated with a group of Gallup scientists who unveiled the results of a landmark 30 -year research project that ignited a global conversation on the topic of strengths (Rath and Conchie 2008). Gallup scientists surveyed more than one million work teams and conducted more than 20,000 in-depth interviews with leaders and with 10,000 employees. The most effective leaders invested in their employees' strengths. Spending time building strengths was far more productive than logging countless hours shoring up weaknesses.

Closer to home, nurses who feel appreciated and recognized for their expertise are more likely to stay in their jobs and experience high job satisfaction (SullivanHavens and Aiken 1999). Nurse leaders are key to creating and sustaining positive professional practice environments that lead to better patient care (MacPhee et al. 2011; Needleman et al. 2011a,b; O’Brien-Pallas et al. 2010).

\section{A New Vision for Nursing: Strengths-Based Nursing Care}

The strengths-based approach is about expanding the imaginary horizons of the nurse at the bedside, nurse managers and nurse leaders. It requires a new set of values that allow for innovative solutions to long-standing problems. It requires a new imagining of the world that considers strengths - what is best, what is working and what has potential. It requires a shift in focus from health professionalassessed outcomes to client outcomes. In the current problem-based model, the most important outcomes are patient satisfaction and rates of mortality and morbidity (Wong and Cummings 2007). Strengths-based outcomes are concerned with the human spirit and the whole person and would enlarge the spotlight to include health, healing, quality of life and subjective well-being. 
$\mathrm{SBC}$ is about understanding, uncovering, discovering and releasing biological, intrapersonal, interpersonal and social strengths to deal with challenges and to meet personal, team and system goals. This new approach does not ignore problems nor pretend that weaknesses and deficits do not exist. Rather, a strengths approach is about working with strengths to deal with problems and deficits. It is about working with people, teams and systems to get the most out of what is important and meaningful to them. It is about restoring the centrality of the nurse-person relationship to promote health and to facilitate healing and in so doing, enhance professional nursing practice.

$\mathrm{SBC}$ is a theoretical perspective to guide system transformation under one umbrella (Gottlieb 2012). This theoretical perspective

- places the person and family at the centre of care (Person/Family-Centred Care);

- empowers the person/family to achieve their own goals and find new meaning in their lives (Empowerment Movement);

- requires an understanding of the whole person and considers human uniqueness from cells to citizens to communities (Whole-Person Care, Holistic Care, Personalized Care);

- requires that issues be understood within their context, taking into account history and circumstances (Context-based);

- encourages the person to take charge of, and be responsible for, his or her own health, recovery and healing (Health Promotion and Illness Prevention, Self-Care);

- requires a collaborative relationship between the person/family and the healthcare provider (Collaborative Partnership).

Just as nurse clinicians have to create environments to help people become empowered to take control over their healthcare, in the same way nurse leaders must create environments to enable nurses to become empowered to practise SBC.

\section{Strengths-Based Nursing Leadership}

Strengths-Based Nursing Care and Strengths-Based Nursing Leadership are not completely new concepts. In fact, the foundations of modern nursing are rooted in strengths-based thinking. Upon reflecting on Florence Nightingale's approach to nursing and what made her a visionary, we see elements of a "strengths-based approach" in her thinking and in her solutions to long-standing problems. We just have to consider Nightingale's most famous quotation, in which she sets down the role of nursing "to put the patient in the best condition for nature to act upon him" (Nightingale 1860: 133). To fulfill this mandate, nurses require knowledge of people's innate healing mechanisms, i.e., biological and psycho-social strengths, as well as knowledge of how to create environments to enable them to heal. In tackling problems of public health, Nightingale used a strengths-based approach based 
on knowledge of people, their environments and the political and social structures to create policy (Dossey et al. 2005). Over the years, nursing got sidetracked from Nightingale's vision. SBC is a way to help nursing regain its foothold in the healthcare system, to move it forward and steer both nursing and the healthcare system in a new direction.

Although not explicitly identified as strengths-based, the nursing leaders who created the magnet hospitals were in effect practising elements of Strengths-Based Nursing Leadership. Before the healthcare crisis, magnet hospitals held enormous promise of what nursing could do and the impact nurses could have on humanizing the healthcare system and meeting the healthcare needs of populations (Kramer 1990). The late Joyce Clifford, nurse maverick, in her role as chief nurse of Boston's Beth Israel Hospital, showed how to transform a system by creating organizational structures and work environments that empowered nurses to practise to the full scope of their knowledge, competencies and skills (Clifford 1998). Magnet hospital nursing leaders created positions and a workplace environment that gave nurses the opportunities, resources, power and status to shape and control their own practice (Kramer et al. 2007). More recently, the concepts of empowerment and transformational leadership have some strengths-based elements as their underpinnings (Laschinger et al. 2006; White and O’Brien-Pallas 2010).

\section{Principles of Strengths-Based Nursing Leadership}

The principles of Strengths-Based Nursing Leadership are consistent with the values underlying SBC (Gottlieb 2012). Principles are a reflection of the leader's vision and serve as the compass to guide decisions and direct actions.

There are eight principles of Strengths-Based Nursing Leadership. Although the principles are interrelated because they are built on ideals of empowerment and equity, each has its own distinct focus.

Principle \#1: Strengths-Based Nursing Leadership works with the whole while appreciating the interrelationships among its parts

A defining quality of a leader is that he or she must have a vision. Leaders, through communication and action, impart the vision and help nurses to understand how the pieces contribute to the whole. In other words, leaders help others to "find meaning in piecemeal actions and to make those connections for others so they can see the macro level while dealing with the micro level” (McBride 1994: 284).

Leaders also understand the interrelationship between the whole and its parts. What constitutes the whole and its parts depend on the issue. For example, the whole can be the institution and its parts are then the organization's units. The whole can also be the healthcare system or the community, while the part is then 
the institution. Thus, leaders need to understand the niche that their institution fills within the larger system, and lead accordingly.

Strengths-Based Nursing Leadership is transformational leadership. One of the competencies of transformational leadership is the management of attention (Bennis 1990). A strengths-based leader understands what is relevant for the present and future, what is salient and what requires attention. Strengths-based nursing leaders are continuously taking stock of strengths: what strengths are present, where to build strengths, how strengths in one area can be used to scaffold, complement, or compensate another, and the like. The current popular concept of Talent Management is completely aligned with this principle (Berger and Berger 2010).

Principle \#2: Strengths-Based Nursing Leadership recognizes the uniqueness of staff, nurse leaders and the organization

Strengths-Based Nursing Leadership understands that no two people are alike (Harris 2006) and that each brings to the organization his or her unique set of strengths as well as limitations. Leaders understand that they are creating and building a community requiring professionals with different expertise, knowledge and skills to meet the multitude and complex needs of the population. It is the leaders' responsibility to bring individuals to work together with the right mix of strengths to realize their vision and meet patient/family needs. To do so, leaders need to know the existing talents of their staff and identify potentials that can be developed into strengths through training, education and experience.

Among the attributes of a best-run business and a magnet hospital are respecting and valuing the individual, treating people with dignity and providing positive feedback about what they are doing best and how to do better (Upenieks 2003). Furthermore, in order to treat nurses in this manner, leaders must have the skills to recognize, uncover and discover strengths, and then to mobilize and capitalize on them. It is also equally important to understand one person's weaknesses or limitations in order to supplement or compensate with another person's strengths. Leaders also understand the importance of not only celebrating successes but the value of learning from mistakes as a way to develop strengths (Davey et al. 2009; Tourangeau et al. 2010).

Leaders must have self-knowledge (McBride 2011). They need to surround themselves with a team that complements their own strengths, and compensates for the skills that they lack, in order to minimize their own limitations or weaknesses. They allow the team to shine because they know that it takes a team to realize a vision.

Principle \#3: Strengths-Based Nursing Leadership creates work environments that promote nurses' health and facilitates their development Strengths-Based Leadership is concerned about building healthy workplaces. After 
a decade of research, the positive and negative effects of healthy and unhealthy workplaces on nurses and patients have been well documented. Unhealthy workplace environments have contributed to high rates of nurse burnout, dissatisfaction and absenteeism, poor physical and mental health and difficulty attracting and retaining nurses (Laschinger et al., 2003; White and O'Brien-Pallas 2010). Moreover, unhealthy workplaces have compromised patient safety and put patients at risk for higher rates of morbidity and mortality (Aiken et al. 2002). Following these disturbing revelations, a decade of research ensued to identify characteristics of healthy environments and the organizational structures and leadership practices that made this happen (Armstrong et al. 2009). Strengthsbased leaders know how to put structures in place to empower nurses to control their own practice by encouraging autonomy and positive professional relationships, particularly with physicians.

Another aspect of Strengths-Based Nursing Leadership is subscribing to the idea of health as a process of becoming (Gottlieb 2012). Every individual and department in an institution or agency needs help to develop and grow if they are to realize their potential. When nurses are given the opportunities to do their best and be their best, they will reciprocate in kind (McBride 2011). Strengths-Based Nursing Leadership also values creating healing environments for nurses, where nurses feel physically and emotionally safe and secure (Shirey 2006).

Strengths-Based Nursing Leadership goes beyond attending to structures. Leaders treat nurses as assets to be developed, not managed. They encourage relationships and create experiences that bring out the best in their nurses and in which nurses strive to do their best. They do so with purpose and with compassion, humility, curiosity, mindfulness and self-reflection (Gardner et al. 2011; Gottlieb 2012). Thus, strengths-based leaders "get it." They understand that their best investment is investing in people and relationships and securing resources to do so.

Principle \#4: Strengths-Based Nursing Leadership understands the significance of subjective reality and created meaning

One of the major challenges of leadership is how best to deal with multiple perspectives. Leaders are constantly challenged to examine and entertain many different viewpoints, some that may be consistent and compatible while others that may be contradictory. Why is this so?

Humans "construct" knowledge, create their own reality, find different ways to find meaning and "dwell" in different situations. People operate from their own worldview of reality that has been constructed or has arisen from their own unique experiences, knowledge and understandings. 
The same principle operates within and across a profession and within and across departments of an institution. For example, even within the same profession, individuals and groups of individuals can hold different viewpoints and values, subscribe to different interpretations of the same event and operate from different patient care models. These differences often affect how issues are framed, decisions made and solutions advanced.

Strengths-Based Nursing Leadership is aware of and works with this aspect of human development to advantage. Strengths-based leaders strive to understand multiple positions, find common ground in differences and make a concerted effort to consider multiple viewpoints. They are able to entertain and hold contradictory perspectives because they understand that, often, opposable ideas give rise to the most creative and innovative solutions (Martin 2007). In other words, Strengths-Based Nursing Leadership celebrates and encourages diversity in thought because of its inherent strength in creating an innovative and exciting climate for professional nursing development.

Principle \#5: Strengths-Based Nursing Leadership values self-determination Self-determination is the ability to choose without coercion. It is required to meet an individual's basic needs for autonomy, competence and relatedness (Deci and Ryan 1985). These are critical strengths that define professional nursing practice (Scott et al. 1999).

People who are able to engage in self-determination are more likely to be motivated to do their best. This is because they experience greater freedom to act in accordance with their own values and beliefs, meet personal and professional goals, act in ways that reflect aspects of themselves and are interested in and enjoy what they do (Williams et al. 1996). Work environments that promote self-determination have employees who report high job satisfaction, have positive workrelated attitudes, are more effective and creative in their job and have higher levels of psychological health and well-being (Gagné and Deci 2005).

Strengths-Based Nursing Leadership creates conditions to further develop skills of autonomy, competence and relatedness by providing positive and meaningful feedback and opportunities to exercise and engage in choice.

Principle \#6: Strengths-Based Nursing Leadership recognizes that person and environment are integral and that nurses function best in environments where there is a "goodness of fit" that capitalizes on their strengths

During the past 40 years, there has been an impressive body of research into the pivotal role of nursing leadership for creating the structures and climates that foster healthy or toxic workplaces (Kramer et al. 2010; Pearson et al. 2007). 
Strengths-Based Nursing Leadership subscribes to a transactional perspective of environment in which the person influences and is influenced by the physical and social environments in which they live and work.

Research has focused on "mismatches" between person and position and the effects on nurse burnout and dissatisfaction (Greco et al. 2006). Mismatch occurs when the nurse does not have the knowledge or skills required for the position. It also occurs when the workplace does not fully utilize the nurses' knowledge and competencies, creates unrealistic workloads whereby nurses are thwarted from practising to the best of their strengths, and so forth (IOM 2010). Conversely, matched environments of person-job fit have an empowering effect and promote engagement (Laschinger et al. 2006).

Strengths-Based Nursing Leadership focuses on "goodness of fit" or "person-position fit." This happens when nurse leaders create opportunities that best utilize those strengths for the task at hand. It occurs when leaders place nurses in positions or create positions that align with the nurse's passions and skills, as well as give them the opportunities, support and resources to perform at their best and to realize their potential. This happens when strengths are intentionally targeted and utilized (Traynor et al. 2010). Thus, the best human resource policy is to match the person to positions that bring forth his or her strengths.

Principle \#7: Strengths-Based Nursing Leadership creates environments that promote learning and recognizes the importance of readiness and timing In the rapidly changing world of healthcare and nursing, workplaces have to become continuous learning environments, and nurses have to embrace and embark on a lifelong journey of learning.

Strengths-Based Nursing Leadership understands that knowledge is power and that if nursing is to have power, it requires well-educated, dedicated, compassionate and knowledgeable nurses. Leaders understand the importance of transforming their departments into learning environments where knowledge, information, self-awareness and research are valued activities because they know that high-quality practice is inextricably linked to these activities. They encourage self-reflection and mindful practice because these are important tools to selfknowledge and self-improvement.

Strengths-based leaders recognize that nurses need mentors and preceptors to coach them to profit from what others have learned in practice, to assist them to acquire the knowledge and skills needed to develop expertise in a given field and to benefit from learning from mistakes (Benner et al. 2010). Moreover, they 
understand the importance of dedicating resources and putting structures in place to encourage employees' ongoing learning (Kramer et al. 2010).

Another characteristic of Strengths-Based Nursing Leadership is the ability to anticipate change and to prepare staff to be ready for change. Indeed, all organizations, whether in the public or private sector, need to be able to respond appropriately with the right skill set and at the right time. However, while strengths-based leaders can prepare their organization and staff for change, a critical strength is knowing when it is the right time to make a decision.

Principle \#8: Strengths-Based Nursing Leadership invests in collaborative partnerships

Strengths-Based Nursing Leadership values collaborative partnership because, in almost every partnership, all partners benefit to varying degrees (Gottlieb and Feeley 2006; Zwarenstein et al. 2009). This is particularly the case when partnerships are built on negotiated goals, shared power, openness and respect. Collaborative partnership is consistent with a strengths-based approach. It is built on elements that bring to the table each partner's respective talents and expertise to meet goals and work with purpose and intention in a meaningful way.

Collaborative partnership focuses on what each partner does best. It involves helping the other partner maximize his or her talents and potentials. It is an approach that engenders confidence by promoting competence. It is premised on investing in relationships and learning to trust in oneself and in one's partner (Sofarelli and Brown 1997). Collaborative partnership requires that each partner finds his or her own voice, defends his or her position and brings evidence on which to base sound clinical decisions (Schmalenburg et al. 2005).

\section{Imagining the Future}

Both the healthcare system and nursing are at a crossroad. Nursing can and should become a major player in turning the healthcare system around. Nurses can do so by providing the vision, creating the direction and leading the way. As the healthcare system transforms itself, nursing faces a choice. It can wait to see how things unfold and how nurses will fit into the new system once it takes shape; or, nursing can lead the way. The profession can do so by setting forth a new vision rooted in nursing values of holism and restoring the centrality of the nurse-person relationship as expressed through a strengths-based approach.

Nurses and nursing are well positioned to transform the healthcare system because of their numbers, their scope of practice to carry out many roles and their ability to care for people of all ages across the continuum of care in health and 
sickness and in different settings. They have a history of inspired leadership in Nightingale, who showed what could be accomplished with vision, conviction and the willingness to challenge the status quo.

Strengths-Based Nursing Leadership provides the model to move forward and for nurses and nursing to seize the day - carpe diem. The stars are in the right alignment for nursing and nurses to step forward and create a more holistic, humanistic, integrated, health-based healthcare system for the 21st century by focusing on what is best, what works and what has potential.

Correspondence may be directed to: Laurie N. Gottlieb, professor, School of Nursing, McGill University, 3506 University Street, Montreal, Quebec, Canada H3A 2A7. E-mail: laurie.gottlieb@mcgill.ca.Phone: 514-398-4164.

\section{References}

Aiken, L.H., S.P. Clarke, D.M. Sloane, J. Sochalski and J.H. Silber. 2002. "Hospital Nurse-Staffing and Patient Mortality, Nurse Burnout and Job Dissatisfaction." Journal of the American Medical Association 288(16): 1987-93.

Armstrong, K.M., H.K.S. Laschinger and C.A. Wong. 2009. "Workplace Empowerment and Magnet Hospital Characteristics as Predictors of Patient Safety Climate." Journal of Nursing Care Quarterly 24(1): 55-62.

Benner, P., M. Sutphen, V. Leonard and L. Day. 2010. Educating Nurses: A Call for Radical Transformation. San Francisco: Jossey-Bass.

Bennis, W. 1990. Why Leaders Can't Lead. San Francisco: Jossey-Bass.

Berger, L.A. and D. Berger. 2010. The Talent Management Handbook: Creating a Sustainable Competitive Advantage by Selecting, Developing and Promoting the Best People. New York: McGraw Hill.

Clifford, J.C. 1998. Restructuring: The Impact of Hospital Organization on Nursing Leadership. Chicago: AHA Press.

Davey, M., G. Cummings, C. Newburn-Cook and E. Lo. 2009. "Predictors of Nurse Absenteeism in Hospitals: A Systematic Review.” Journal of Nursing Management 17: 312-30.

Deci, E.L. and R.M. Ryan. 1985. Intrinsic Motivation and Self-Determination in Human Behavior. New York: Plenum.

Dossey, B.M., L.C. Selanders, D.-M. Beck and A. Attewell. 2005. Florence Nightingale Today: Healing, Leadership, Global Action. Washington, DC: American Nurses Association.

Frist, W.H. 2005. "Health Care in the 21st Century." New England Journal of Medicine 352: 267-72.

Gagné, M. and E.L. Deci. 2005. “Self-Determination Theory and Work Motivation.” Journal of Organizational Behavior 26: 331-62.

Gardner, W.L., C.C. Cogliser, K.M. Davis and M.P. Dickens. 2011. “Authentic Leadership: A Review of the Literature and Research Agenda." Leadership Quarterly 22: 1120-45.

Gilbert, J.H.V., J. Yan and S.J. Hoffman 2010. Framework for Action on Interprofessional Education and Collaborative Practice. Geneva: World Health Organization.

Gottlieb, L.N. 2012. Strengths-Based Nursing Care: Health and Healing for Person and Family. New York: Springer.

Gottlieb, L.N. and N. Feeley (with C. Dalton). 2006. The Collaborative Partnership Approach to Care: A Delicate Balance. Toronto: Elsevier/Mosby. 
Greco, P., H.S.K. Laschinger and C.A. Wong. 2006. "Leader Empowering Behaviours, Staff Nurse Empowerment and Work Engagement/Burnout." Canadian Journal of Nursing Leadership 19(4): $41-56$.

Hancock, T. 1999. "Health Care Reform and Reform for Health: Creating a Health System for Communities in the 21st Century." Futures 31(5): 417-36.

Harris, J.R. 2006. No Two Alike: Human Nature and Human Individuality. New York: W.W. Norton.

Institute of Medicine (IOM). 2010. The Future of Nursing Leading Change, Advancing Health. Washington, DC: National Academy Press.

Institute of Medicine (IOM). 2012. For the Public's Health: Investing in a Healthier Future.

Washington, DC: National Academy Press.

Kramer, M. 1990. "The Magnet Hospitals: Excellence Revisited." Journal of Nursing Administration 20(9): 35-44.

Kramer, M., P. Maguire, C. Schmalenberg, B. Andrews, R. Burke, L. Chmielewski, M.A. Donohue, M. Ellsworth, D. Poduska, M.E. Smith and C. Tachibana. 2007. "Excellence through Evidence: Structures Enabling Clinical Autonomy." Journal of Nursing Administration 37(1): 41-52.

Kramer, M., C. Schmalenberg and P. Maguire. 2010. "Nine Structures and Leadership Practices Essential for a Magnet (Healthy) Work Environment." Nursing Administration Quarterly 34(1): 4-17.

Laschinger, H.K.S., J. Finegan, J. Shamian and P. Wilk. 2003. "Workplace Empowerment as a Predictor of Nurse Burnout in Restructured Healthcare Settings." Longwoods Review 1(30): 2-11.

Laschinger, H.K.S., C.A. Wong and P. Greco. 2006. "The Impact of Staff Nurse Empowerment on Person-Job Fit and Work Engagement/Burnout." Nursing Administration Quarterly 30(4): 358-67.

Lewis, C.K. and J.H. Mathews. 1998. Magnet Program Designates Exceptional Nursing Service." American Journal of Nursing 98(12): 51-52.

MacPhee, M., A. Wardrop, C. Campbell and P. Wejr. 2011. "The Synergy Professional Practice Model and Its Patient Characteristics Tool." Canadian Journal of Nursing Leadership 24(3): 42-56.

Martin, R. 2007. The Opposable Mind: How Successful Leaders Win through Integrative Thinking. Cambridge, MA: Harvard Business School Press.

McBride, A.B. 1994. “Transformational Leadership.” Nursing Outlook 42: 284.

McBride, A.B. 2011. The Growth and Development of Nurse Leaders. New York: Springer.

McKay, C.A. and L. Crippen. 2008. "Collaboration through Clinical Integration.” Nursing Administration Quarterly 32(2): 109-16.

Nightingale, F. 1860. Notes on Nursing: What It Is and What It Is Not. London, UK: Harrison.

Needleman, J., P. Buerhaus, S. Maureen, S. Zelevinsky and S. Mattke. 2011a. "Nurse Staffing in Hospitals: Is There a Business Case for Quality?" Health Affairs 25(1): 201-11.

Needleman, J., P. Buerhaus, S. Pankratz, C. Leibson and S. Stevens. 2011b (March 17). "Nurse Staffing and Inpatient Hospital Mortality." New England Journal of Medicine 364: 1037-45.

O’Brien-Pallas, L., G. Tomblin Murphy, J. Shamian, X. Li and L. Hayes. 2010. "Impact and Determinants of Nurse Turnover: A Pan-Canadian Study." Journal of Nursing Management 18: 1073-86.

Organisation for Economic and Co-operative Development (OECD). 2011. Health Data. Paris.

Pearson, A., H.S.K. Laschinger, K. Porritt, Z. Jordan, D. Tucker and L. Long. 2007. “Comprehensive Systematic Review of Evidence on Developing and Sustaining Nursing Leadership That Fosters a Healthy Work Environment in Healthcare." International Journal of Evidence Based Healthcare 5: $208-53$.

Rath, T. and B. Conchie. 2008. Strengths-Based Leadership. New York: Gallup Press.

Schmalenberg, C., M. Kramer, C.R. King, M. Krugman, C. Lund, D. Poduska and D. Rapp. 2005.

"Excellence through Evidence: Securing Collegial/Collaborative Nurse-Physician Relationships, Part 1." Journal of Nursing Administration 35(10): 450-57. 
Scott, J.G., J. Sochalski and L.H. Aiken. 1999. "Review of Magnet Hospital Research: Findings and Implication for Professional Nursing Practice." Journal of Nursing Administration 29(1): 9-19.

Shirey, M. 2006. "Authentic Leaders Creating Healthy Work Environments for Nursing Practice." American Journal of Critical Care 15(3): 256-67.

Sofarelli, D. and D. Brown. 1998. “The Need of Nursing Leadership in Uncertain Times.” Journal of Nursing Management 6: 201-7.

Sullivan-Havens, D. and L.H. Aikens. 1999. "Shaping Systems to Promote Desired Outcomes: The Magnet Hospital.” Journal of Nursing Administration 29(2): 14-19.

Tourangeau, A., L. Cranley, S. Laschinger and J. Pachis. 2010. “Relationships among Leadership Practices, Work Environments, Staff Communication and Outcomes in Long-Term Care." Journal of Nursing Management 18(8): 1060-72.

Traynor, A.P., K.H. Janke and T.D. Sorensen. 2010. "Using Personal Strengths with Intention in Pharmacy: Implications for Pharmacists, Managers and Leaders." Annals of Pharmacotherapy 44: $367-75$.

Upenieks, V.V. 2003. “The Interrelationship of Organizational Characteristics of Magnet Hospitals, Nursing Leadership and Nursing Job Satisfaction." Health Care Manager 22(2): 83-89.

Vahey, D.C., L.H. Aiken, D.M. Sloane, S.P. Clarke and D. Vargas. 2004. "Nurse Burnout and Patient Satisfaction." Medical Care 42(2): 57-66.

White, S. and L. O'Brien-Pallas. 2010. The Healthy Work Environments Best Practice Guidelines pilot Evaluation Final Report: Degree of Presence of Recommendations in Action in Nursing Practice and Nursing Work Settings. Toronto: RNAO.

Williams, G.C., E.L. Deci and R.M. Ryan. 1998. "Building Health-Care Partnerships by Supporting Autonomy: Promoting Maintained Behavior Change and Positive Health Outcomes." In A.L. Suchman, P. Hinton-Walker and R. Botelho, eds., Partnerships in Healthcare: Transforming Relational Process (pp. 67-87). Rochester, NY: University of Rochester Press.

Wong, C.A. and G.G. Cummings. 2007. "The Relationship between Nursing Leadership and Patient Outcomes: A Systematic Review." Journal of Nursing Management 15: 508-21.

Zwarenstein, M., J. Goldman and S. Reeves. 2009. "Inter-professional Collaboration: Effects of Practice-Based Interventions on Professional Practice and Healthcare Outcomes." Review. Cochrane Library 3: 1-30. 